\title{
Applied Ethics and Modern Enterprises-One Viewpoint
}

\author{
Zoran Nikolic, Zorana Nikolic Maksimovic \\ University Business Academy, Novi Sad, Serbia
}

\begin{abstract}
Business ethics has been growing from a philosophy discipline to an applied science. That explains its significance for more efficient functioning of various systems in business world. For that reason, organized societies with developed economies invest in empiric, theoretic, and theoretic-empiric investigations of various sectors and applied dimensions of business ethics. Its epistemological sense reflects to increasing productivity, more successful establishing of the system of hierarchy within an enterprise, appropriate formulating the strategy of management, improving the market reputation, increasing profitability, and strengthening social responsibility. The complexity of modern and successful business is based on a series of social factors which spread in the arch from anthropological, socially-psychological, and cultural characteristics of a human being, to quality characteristics of the global society. That is why the scientific information available to business ethics is synthesized from various scientific perspectives. This paradigm is a starting point of this project which is about the above subject. Its cognitive aim is presented through the description, classification, and explanation of the influence of business ethics to successful functioning of every kind of business institution. As a theoretic investigation which grows from verified scientific information and their critical analysis, it relies on standard, general scientific, basic special and general methods which are characteristic to the applied scientific disciplines. Business ethics has clearly established two key cognitive bases of its investigations: 1) personal value attitude; and 2) interests of a company, groups, and individuals in them. This project is only a small contribution to explaining elementary functions of this applied ethics in business world.
\end{abstract}

Keywords: business ethics, applied science, business culture, management strategy, system of relations, interest of an enterprise

\section{Introductory and Methodological Notes}

The sense of business ethics reflects to its cognitive ability to practically apply its knowledge. In that way, it directly assists an enterprise to function more successfully and efficiently, to provide the morality of acting in all the levels of business and to strengthen social responsibility. Its sense builds its significance as an applied scientific discipline which does a useful social function. It has to pervade every segment of a firm. Such the ethics is absolute because it is expected to be applied constantly. Its application depends on the obtained knowledge, in the context of micro and macro social and business conditions. Micro-conditions refer to the system of relations in a business organization and macro-conditions relate to a wider range of social

Zoran Nikolic, full-time professor, Faculty of Economics and Engineering Management, University Business Academy, Novi Sad, Serbia.

Zorana Nikolic Maksimovic, master lawyer, unemployed, University Business Academy, Novi Sad, Serbia.

Correspondence concerning this paper should be addressed to Zoran Nikolic, Faculty of Economics and Engineering Management, University Business Academy, Street Cvećarska No. 2, Novi Sad 21000, Serbia. 
circumstances and social influences to business and business ethics. If its application is based on these assumptions, then its success can be expected.

Balanced, harmonious, and professional relations in an enterprise strengthen its stability and professional capacity. And by that, its competitiveness at the market increases, too. That is why some writers point out that it is one of the most important roles of business ethics (Nordstrom \& Ridderstrale, 1999, pp. 281-282). Moral norms are equal for everybody. They refer equally to all and they have to be applied to each person. Of course, the norms are not the same in every culture, every society, space, and time. That is why we talk about the relativity of moral. In order to apply the study of business ethics and in order to implement it in the practice of enterprises, it is necessary to valorize it through specific models which would standardize the acting of the employed according to the moral ${ }^{1}$. And that is usually done through ethical programs, procedures of resolving ethical issues, ethical codices, and corporation codices. With the same purposes, ethical boards (ethical committees) are founded, and they are mostly organic parts of administrative boards of enterprises. The professions dedicated to working on a moral organization of enterprises are established, ethical trainings are held and ethical education of the employed is performed, the mechanisms of keeping relations among the employed and those ones who in the first degree take care of the morality of acting are determined etc. There are also the cases when the institutions, which do the works which are exclusively in the domain of business ethics, are founded. Of course, we should not neglect the scientific institutes which study the complex and sensitive questions of ethics in business.

The work has been founded as a theoretical research based on the examined and confirmed scientific attitudes about scientific and social character of business ethics, conditions of its development and practical application. The subject of researching is operated as the role of business ethics in a successful planning, organizing and implementation of any kind of business activity through the establishment of an appropriate strategy of management and establishing the system of relations among the employed. The description, typology, and explanation of the way in which this applied science directly causes successful functioning of a business institution in all, and especially in the aspects of interest, are emphasized as central aims of the cognition. For that purpose we have constituted the following individual hypotheses:

- the sense of business ethics is contained in the practical contribution to more successful and more profitable functioning of business institutions,

- business ethics contributes to strengthening social responsibility,

- institutionalized and standardized ways of acting according to moral principles and norms improve the competitiveness of an enterprise at the market,

- respecting moral principles in business is the assumption of respecting the market laws,

- verified scientific information of business ethics causes establishing an efficient system of business,

- scientific-theoretical knowledge of this applied ethics enables regular formulation of the strategies of management and relationship with employees,

- developing the relations in a firm, which are based on moral principles, provides a higher level of motivation of employees and with that, a better productivity,

- business ethics directly influences the reputation of a business institution as a valued and interest category.

\footnotetext{
${ }^{1}$ See: Crane, A., \& Matten, D. (2004). Business Ethics: A European Perspective, Oxford University Press, New York, p. 144.
} 
The subject of the study and the established cognitive aims of work determined the use of the methods in various stages of investigation. The methods used as fundamental ones were: generalization, induction, and synthesis, and of general scientific methods the authors decided to use the axiomatic and comparative methods. Since it is about a theoretical research, in the procedure of collecting data, the method of document analysis was primarily used. It is about official and public sources of data. The predicative indicators served us to set individual hypothesis as correct as possible. In the investigation, we operated logical and predicative constants. In the procedure of arranging and displaying the date we leant on the standard methods of classification and the method of correlation. The analysis of collected material was published with the help of the comparative method.

\section{Functions of Business Ethics as an Applied Science}

Business ethics does a series of useful social functions which can be regarded through two basic aspects: a) the functions that refer to an enterprise; and b) functions that refer to employees and other participants in some part of business activities.

If we start from the function of business ethics that refer to an enterprise, we highlight:

(1) Participation in defining the strategy of doing business and management of an enterprise. In our opinion this is one of the most important roles done by business ethics. By its scientific knowledge, business ethics contributes the strategy of doing business and management to be formulated as successful as possible, starting from both moral principles and moral norms. In that way it creates such the atmosphere in a collective which is optimal and complete devotion to business activity on internal and external plan. By that, it significantly strengthens the mutual trust of the employed, their solidarity and loyalty to the firm. When motives are increased, better results will be achieved as well as higher profit will be realized.

(2) Establishing moral relations among employees, clients, associates, and business partners. This function is founded on the previous one, and represents its practical concretization. The consequences produced by it are identical to those ones in the said example.

(3) Stability of functioning and development of an enterprise. The business environment without tensions, arguments, and conflicts, without wasting work and creative energy and money on resolving frequent and rather serious problems, contributes a business organization to function by economic commands and according to social norms. Balanced business relations within an enterprise reflect positively to the relations with clients and associates. All that create necessary conditions for a desirable development of the firm.

(4) Providing cognitive frames, ways, and means for approving an ethics program, ethics and corporation codex. Business ethics obtains and applies its knowledge. That aim is first realized regarding the approval of those documents which standardize moral acting in doing business of an enterprise. It is not enough only to issue the program and codices, but to know how to adapt their contents to the character of the organization and the set of more general social circumstances. Besides that, business ethics formulates the ways, as well as the techniques (acting and means) of practicing ethics programs, ethics and/or corporation codices.

(5) Establishing the content and the way of ethics training. Without a professional training of the employed in an enterprise, standardization of ethical business would be mostly reduced to improvisation. As it is about a complex and sensitive topic, it is necessary for this kind of activity to be completely professionalized. That means that it would be performed by the persons who are educated to devote to the practical application of business ethics knowledge. For that kind of activities specialized institutions for only those activities can be 
engaged, or some specific educational and professional profile in firms would be trained for successfully doing that job. Depending on the range, financial ability of a firm, as well as the appropriate understanding the seriousness of this profession, in an enterprise, that job would be given to a professional team, or, possibly to an individual. Besides these bases which determine the firm in which extent the activities of business ethics will be institutionalized within the firm, the leaders of a firm (directors, managers) ${ }^{2}$ have a significant influence. Their consciousness about the importance of business ethics, discernment, and readiness to face unethical phenomena, influence the level of the presence of this profession and activity in an enterprise. And also whether it will exist at all, in which way it will function and with which formal, or maybe, informal objectives and so on.

(6) Strengthening personal and social responsibility. Moral considerations and moral acting in each collective directly influence the strengthening personal responsibility of each member of that collective. In that sense social responsibility is developed, too. It is important not only for a social community but also for business functioning of an enterprise. As a result of these processes, other positive processes for a business organization appear.

(7) Establishing business atmosphere which contributes the development of the competitiveness of an enterprise at market. It is about the environment in which a firm can devote itself and its market opportunities. Considering the mentioned advantages of the institutionalization of moral standards, it is clear that in that way, it will become more serious competitor to other similar enterprises at market. The trust of consumers, business partners, and associates, the quality of goods and services, their acceptable price and enough quantity, result in a good and reliable market position ${ }^{3}$.

(8) Contribution to more stable functioning of the market laws. This role is also derived from the previous one done by business ethics. If such a practice stabilizes in the business world and if it appears as a rule which is assumed and becomes a custom behavior, then the laws of market will function in their full extent.

(9) Strengthening productivity and profitability of an enterprise. The sense of personal value and importance for a collective develops the satisfaction of employees, the sense of belonging to a team and strengthens their motivation to work. The persons become more professional and devoted to their activities. Productivity also increases with these facts and then profitability, too. Of course, if there are no other complicating circumstances, primarily from the outer surroundings such as: reducing the demands for our goods of services, economic crisis in the country and internationally, international isolation of the country, complete restructuring of the economy, inflation etc.

(10) Creating a desirable image of an enterprise. A successful, firm, and stable enterprise creates a good image about itself. It is the most important recommendation for the market ${ }^{4}$.

(11) Improving the reputation of an enterprise on a local, state and international plan. The reputation and the image of an enterprise go hand in hand. Business reputation is the identity cart at market. If enterprises identify themselves through the reputation in business, their competitive and market abilities will increase.

\footnotetext{
2 See: Daft, R. L., \& Marcic, D. (2009). Understanding Management, Mason, South-Western Cengage Learning, Ohio.

3 Many authors write about the significance of business ethics for the satisfaction of consumers and strengthening competitiveness at market. Even in the late eighties J. Singh pointed out that subject. Referring to the European study about the attitudes of consumers he emphasized that over $70 \%$ of the examinees decided the response that a basic criterion for buying some goods is the knowledge that its manufacturer respects business ethics. Singh, Jang, B. (1989). The Teaching of Ethics in Canadian Schools of Managements and Administrative Studies, Journal of Business Ethics, pp. 51-56.

4 Abd-El-Salam, E. M., Shawky, A. Y., \& El-Nahas, T. (2013). The impact of corporate image and reputation on service quality, customer satisfaction and customer loyalty: testing the mediating role. Case analysis in an international service company, The Business \& Management Review, Vol. 3 Number 2. pp. 179-180.
} 
(12) Developing the awareness about the necessity of morality in business. One can develop the necessity for his own moral acting according to his personal system of values. He creates his conscientiousness on his consciousness and experience that it is correct to act in a specific way. The will to act morally joins consciousness and experience. He expects that from the others. As a rational being he noticeable in experience thinks and makes a decision about what is correct and what is wrong to do. If he has enough experience arguments that ethics in business brings good both for him and for the others, he will develop the consciousness about the necessity of morality in business.

(13) Establishing the environment in which there is a necessity to respect social standards. As in the previous example, a man notices, thinks, checks on experience and makes conclusions about the usefulness of respecting social standards. He understands social and economic significance of the arranged order which grows on values and social norms. Through rationalization, he joins the useful and the valuable, realizing how and for which reasons these categories are complementary.

(14) Strengthening the sensitivity to moral problems. Cognition and experience of the importance of morality in business, on one side, strengthens human sensitivity to moral problems. The consciousness about values and usefulness of the morally correct in business produces a kind of accustomed behavior. The absence of such standards or their temporary avoiding in a team creates a worry. A man who has realized the sense, importance, and usefulness of one way of acting, and who is constantly being confirmed by experience, will simply notice, feel, and understand its absence.

(15) Development of freedom to express one's own moral worry. As the consciousness of correctness of moral acting is stronger and an official business environment in an enterprise encourages it, in so far a personal freedom to express one's own moral worry is developing, and also the demand for solving such situation in a regular way, according to the standards and procedures which are formalized in the enterprise.

(16) Determining the ways and techniques of preclusions of the violation of moral standards. It is better to prevent than to repair. The sense of this function of business ethics is simply expressed through this proverb. It is better to act before a problem appears. Professionalism, experience, and continuous training of ethics, significantly contribute to the prevention of immoral acting. The atmosphere in a team itself, the level of using moral standards, their experience formalization, and the degree of sensitivity of the employees to moral problems, also influence the determination of mechanisms for prevention of immoral acting in doing business.

(17) Adopting, checking, confirmation, and formalization of the ways and techniques of fast and efficient solving the appeared problems concerning moral. The practice of ethics is in serious question in this functional part, too. The verified scientific information and the experiences of business relations and relationships in a moral perspective give answers to the questions which ways, techniques, and means should be used to discover (if they have not been prevented) moral problems and to solve them as fast and successful as possible.

(18) Determining ethical predispositions for the persons on leaders' positions. Ethics in doing business, besides the established systems, depends on the employees, too. The important role provides higher position in a firm, and with a higher status the possibility to have influence grows. Leaders define the strategy of doing business and management. They are paid to do that. They can formulate the strategy in the context of ethics, but they don't have to. And that is the first level of the power of their influence to the life of a firm. Knowing the relations of the authority and power, we keep in mind that they don't have to stick to the standards of value which are signed by they themselves, or they inherited them. A moral imperative can stay just something that is written. That is why it is necessary to establish the ways and techniques of checking the relations to the 
business ethics of those ones who in any way aspire to come to one of the leaders' positions. The program and codices of ethics can clearly determine the standards of ethics and as well the ways of their checking. However, none of these checks is absolute. That is why practice always gives answers to these questions for the answers of which we cannot be always sure without it.

(19) Establishing the cooperation with a social community. Conscientious, homely business creates presentations about an enterprise with reputation. Every community wants such teams in its surroundings. Of course, conscientiousness is considered to be keeping ecological balance and so many other considerations, too. Employees, associates, and consumers are in such the surroundings. And that is one of the reasons why it is necessary to cooperate with it.

(20) Development of the culture of moral doing business. All these said factors, as well as those ones which have not been mentioned, if they are firmly established and continuously practiced, so we can talk about such moral business from the aspect of business tradition, they create the culture of moral doing business in an enterprise ${ }^{5}$.

If we consider the functions of business ethics related to the employed and other participants in a part of business activity, we make the following conclusions:

(1) Enabling people, through ethical training and other ways, to obtain the consciousness about the importance of ethics in doing business. Establishing systems in order to function according to moral principles and norms and education of individuals to understand the importance of moral acting in doing business is complementary processes. In this way, persons will, besides adopted representations about morality which they have obtained during their upbringing and socialization and their own experience, develop the consciousness about the necessity, sense, and usefulness of practice moral values. If it is about the person who does not have moral habits, by this process he will have the opportunity to realize in which way ethics helps the efficiency and success of doing business, and for the good of all the participants.

(2) Developing the sense of common belonging to a team, solidarity to colleagues, and loyalty to the enterprise. Through education for moral acting and personal business experience, through respecting his personality by others and realizing his useful role as a whole, one makes stronger connections to the team feeling that he is a part of it. One spends a great part of life at work. If he feels pleasure and recognizes his importance there, he will more reliably develop the loyalty to his firm and the solidarity to the colleagues at work, as well.

(3) Developing the devotion to profession, professionalism, and permanent professional education. In the said circumstances the employee feels the need to be as useful part of a team as possible, and his work of high quality. In order to achieve that he realizes that he has continuously obtained new knowledge, attainments, and skills, he has to educate. Besides that, it is necessary to devote himself to his profession in order that he, as an individual, contributes that the team to which he belongs functions in a better way. He will express his professionalism through the relations in all the directions - to the employed, consumers, associates, and business partners.

(4) Creating the standards of acting out of the enterprise. The seriousness of the work we do influences our behavior out of the enterprise. Harmonious relations at work, satisfaction with work atmosphere, relations to us, good salary, reputation of our enterprise and so on demands from us to organize our behavior according to the

\footnotetext{
${ }^{5}$ See: Daft, R. L., \& Marcic, D. (2009), Understanding management, p. 48.
} 
said circumstances, both at our workplace and in the community of which we are members. And in that way, regarding business ethics, we contribute the reputation of our enterprise with all the expected positive feedback.

(5) Development of the need of planning and organizing our obligations at work and out of it. The arrangement of business order makes us have harmonious habits or it confirms them as correct in the value and functional sense.

(6) Obtaining the consciousness about the importance of regulated and just order of an enterprise. As we have pointed out, the consciousness and experience about the existence of the good, and by its importance and usefulness good for the team and for us, directly influence our decision to act in a morally correct way. With that, we will be decisive to protect that order by our work and behavior. By education of the younger to these value coordinates, we help them to learn what we know in the easier and less complicated way. That is how the good, as a value, is standardized in comprehension and practice turning into a sort of tradition of a business team.

\section{System of Relations in an Enterprise}

The functional ability and successful doing business in a firm depend on the established system of relations among the employed. We are interested in a moral dimension of this system of relations. What do we mean by the determinant system of relations? A system is an institutional normative element of a team. It contains specific parts which have to be firmly integrated in the whole. In other words, it is necessary that there exists a factor which unites them and keeps them united, building a system. In this case, it is the system of relations among employees. In a society and various social groups there is always a factor which is the center of integration of parts into the system. That role can be done by a value consensus, an authority, or social rules, for example ${ }^{6}$. There are open and close systems. Open systems have edge elements or channels which spread along the whole system, and which enable mutual influence of the system with the environment. Such things do not happen in close systems. The elements of close systems can be found in the mutual relations only with the other parts of such systems. In rigid close systems there is not even that possibility. The parts do not have any autonomy and possibility for circulation with any other element or that possibility is limited to a determined number of elements.

Regarding this, we can conclude that the system of relations in an enterprise represents its institutional and normative part. Even more precisely, the relations among employees will be institutionalized, i.e. adopted, formalized, and standardized. As being such, they should be in the function of harmonious functioning of a business team and realization of its aims. The normative dimension of the system of relations among employees in an enterprise points out to two facts: a) they grow on some norms of the enterprise, which means that they themselves are standardized; and b) as a standardized part of an enterprise is in the function of its way of realization of the set aims. Norms organize the relations among people and also the way how to, through the behavior of employees and their mutual relations, achieve the intended aims (one or more of them). The parts of the system of relation are their participants - employees, but also the norms (written and unwritten rules), work operations, sectors of business process and administrations. Which of the factors does gather the parts of the system of relations in an enterprise? An enterprise is a business organization. The parts of the system of relations of employees integrate interests, and values can support this integration. A moral system enables the

\footnotetext{
${ }^{6}$ See: Nikolić, Z. (2011). Savremena sociologija, pp. 243-245.
} 
existence of social unities; values are centers of their integrations. However, people in firms provide existence. That is their basic interest. Nevertheless, a business organization is not a moral institution. That does not mean that there should not practice moral acting. If we come from the fact that within an enterprise people gather and integrate on the basis of interest, then we claim that they will do anything which they are convinced that protects and secures their interests (safety of a work place, appropriate working conditions, and a good salary). Business stability and success of an enterprise is the basis of their existential security, too. Owners are focused on better business and realization of more profit. That is completely natural and understandable. Managers are interested in appropriate managing of an enterprise, in order to keep that function and have higher income, more important position, both in the enterprise and in the social community. Therefore, all of them have the same mutual interests. They connect them. Besides the common interests, employees have their own interests but they must not confront the common interests. That is the essence of existing and functioning of every business organization. For that reason we say that it is an interest organization.

As all of them are governed by the common aims and interests, they will do everything that makes the aims be realized and interests be protected. If the practice shows that values can be a rather important factor of business success, then the values will be practiced. In this case we think about generally accepted social values, not the values of a business team which can be harmonized, related, or inconsistent, even opposed to the social values which are based on virtues. We have to be cautious in considering the relations between interests and values, and also the relations of social values and enterprise values. We have made a conclusion that employees estimate what they should do, how to behave, and what kinds of relations they should develop, in order to protect their own interests. These actions are not always based on moral values. But they are not based on the unquestionable opposing to them either. Moral acting is not expressed through absolute determination to do good deeds to others, especially if it is not for their own benefit. Why would anybody in a business organization, where he earns salary, do against himself and for the benefit of somebody else? Morality supposes the appropriate behavior to oneself, too. Simply, you do your job well and that is useful both for you and other participants. Sometimes, other participants in your activity are the buyers of the goods you have manufactured. The quality of goods that you sell them and their satisfaction by that is parts of your business conscientiousness, not only of the skill. And if you sell the quality goods at affordable prices, no matter that, for example, you don't have a competition at least at a local market, then, your acting gets more important moral dimension. And the result of this is that professionalism at work, devotion to a profession and obeying market rules represent completely appropriate moral acting. The most successful companies in the world have built their cultural identities, i.e. business culture. That is what, in the case of the USA, T. Peters and R. Waterman determined even in the seventies of the last century. Their systematization of eight principles that provide a higher level of competitiveness at market and higher profitability of companies is well known ${ }^{7}$. Without corporation culture an enterprise cannot count on good business and desirable position at market. They presented their consideration in the book Corporate Cultures: The Rites and Rituals of Corporate Life ${ }^{8}$. Business ethics is, in the context of its own subject area, devoted to the study of enterprise culture i.e. business culture?

Let's go back to the interest. If one finds out that a strict regime of work is practiced in a firm, and that it somehow usurps his freedom and rights, that the relations among employees are cold and strictly professional,

\footnotetext{
7 Peters, T., \& Waterman, R. H. (2008). U potrazi za izvjesnosnošću, Profil, Zagreb, pp. 45-50.

8 Deal, T. E., \& Kennedy, A. A. (2000). Corporate Cultures: The Rites and Rituals of Corporate Life, Persues Publishing.

9 About this topic you can see in: Nikolić, Z. (2016). Poslovna etika, FIMEK, Novi Sad, pp. 121-125.
} 
that a working process itself is difficult, but that the salaries are excellent, do you think that he will accept such the system of relations? In most cases, he will, no doubt. Why? Because his basic motive in that kind of social group is -interest, before all, the salary. No matter how the conditions of work are difficult and the relations among the employees cold, one mostly accepts them because of the money he receives as his salary and because of the fact that nobody treats him in an immoral way and the conditions of work are equal to everybody. In a society established in this way, people live on their work and they get money for that. With that money they buy what they need for life, educate children, and go on vacations and so on. This is a material world and we have to adapt to it.

That would mean that the discussions about moral in an enterprise are unnecessary? No, they aren't. We only stick to something that exists in experiences. If moral system of relations among employees contributes more successful business of an enterprise and the interest of the employees, then it will be integrated stronger in the existing order of an enterprise. The practice shows that it is one of the most important factors of successful business of a firm. That is why there is so much interest for business ethics in the business world. Let's go now to the other direction. Imagine that immoral relations dominate in a firm and that there is no standardization there. Therefore, the relations among employees who are opposed to moral values and that no social norms are respected in the firm, or they are applied selectively (which means again that they are not respected because the law is equal to all, and so are the other norms). Such the condition would lead to a serious decline of the enterprise, its functioning and reputation. And a reputation is a category of value. That also can be functioning if we come from value frames of doing a specific function. The other reason which is in favor of practicing moral principles and moral norms in behavior and developing mutual relations in an enterprise refers to those reasons which are indicators of the inner atmosphere in an enterprise in which the best results are achieved. What is the importance of satisfaction of the employed and their motivation to productivity and profit of the firm? And those are the two groups of the most important reasons for developing morally valuable relations among the employed in an enterprise. If we analyze these facts we notice that the motives of establishing and practicing moral relations in a business team branch into two groups: 1) Personal value attitude of an individual; and 2) Interest of an enterprise which has business financial and value dimension.

There are several experience variations of the relations of moral system of an enterprise and moral system of a society ${ }^{10}$.

(1) Moral system of a society and moral system of an enterprise are completely identical.

(2) Moral system in a society is in disagreement with the moral system in an enterprise, because the moral system of the enterprise is not founded on the universal moral values both on the other values which are compressed through utilitarian moral and the moral of duty as two types of moral.

(3) Moral system in a society is in disagreement with the moral system in an enterprise, because the moral system of the society is built on quasi values which are different from the well known standards of values and virtues.

(4) Moral systems of a society and of an enterprise are identical, both are built on quasi values which are elevated, promoted, and practiced as real moral values.

\footnotetext{
${ }^{10}$ Don't forget the fact that the system of values represents a structural category which consists of several values of which one represents moral values. Since it is about the structured whole, it really exists in experience if there are all the elements that make the whole of the system of values. It is possible to see that in: Nikolić, Z. (2015). Stavovi stanovnika Vojvodine o načinima zapošljavanja i osnovnim vrednostima u društvu, Zbornik Matice srpske za društvene nauke, 152, pp. 607-608.
} 
These experience variations picture the relations which are being settled on the level of entire society and an enterprise as well. How would we define the system of relations among the employed in an enterprise? A system of relations among employees in a business team is an arranged, formalized, and relatively permanent whole of which the parts are in a harmonious interdependent relation with each other and with the whole, and possibly, with the environment (if it is about open systems). In determining the concept system of relations among employees, we have left out the functional component because there are such systems of relation which are dysfunctional.

\section{Instead of the Conclusion}

The morality of the relations among employees in an enterprise primarily depends on the system of doing business and strategy of management. The relations can depend on characters of individuals, their needs, inclinations, and habits to stick to moral acting. The persons on leader's positions have the opportunity to determine the direction of development of relations among employees, clients, associates, both in moral and in immoral direction. If such acting is in accordance to the presentations about successful business of the owner of capital, then manager will be free in their intentions and actions. If it is done without the consent of the owner of the property, then he is forced to find the ways to hide that kind of activity. He himself is not capable for such activities without the assistance of the others. We consider all that and conclude that nevertheless the system of relations among employees is directly dependant on the system of doing business and the strategy of enterprise management. The will of an individual or more of them, who are in a position to make such important decisions, will direct the total order of doing business of a firm. In that way a system is projecting and building. This system also depends on the existing social standards, cultural and historical characteristics of the time and social space, culture of business and so on. Beside other things, it will also determine ethical dimension of business and of course, human relations, too.

Essential characteristics of a system of doing business and the strategy of management pretty simply and reliably confirm our thesis ${ }^{11}$. It is about related and complementary categories, but not identical. A system of doing business is a wider and more comprehensive category which integrates a management strategy. And in this case, the system represents a union of connecting parts in mutual functional interaction that make a whole. It also can be open and close, like every other system. A system of doing business consists of the following elements: participants (individuals and groups, which depends on the size of an enterprise), aims of business, ways and means of the realization of aims, interactions among the elements, standards, functions, and system functioning, business sectors, enterprise management. Every business system has the aim to function successfully, be well positioned at market, provides its own strength and safety, and growth and development ${ }^{12}$. An enterprise has to determine its aims and sub-aims appropriately, according to its well estimated possibilities at market. A hierarchy organization has to exist among them. The principal aim of each business team is achieving its own interest, but not at the expense of others. Successful business of an enterprise supposes the existence of the following inputs: material resources which are of a permanent character (buildings, equipment,

\footnotetext{
11 Do not equate the term "system of doing business" and "business system". In the text it explained the meaning of the expression system of doing business, while a business system is a denominator for an enterprise as a structured whole.

12 See: Zver, B. (1989). Poduzeće kao poslovni sistem, Zbornik radova Fakulteta organizacije i informatike, p. 246. The same author states the following properties of the system of doing business in an enterprise: dynamics, flexibility, openness, stochastics. Note: stochastics is a skill of guessing the true fact, a measure for probability in prediction.
} 
tools, projects, models etc.) and variable character (raw materials, materials, financials, semi-products, and spare parts etc.), personnel and information resources. The following outputs primarily exist for the same purpose: products, services and information (Zver, 1989, pp. 248-249). The concept of strategy of management comes from the concept strategy. In such a way, the strategy of management could be determined as the activity of systematic planning, organizing, and doing the activity for the purpose of completing the aims of successful managing of the enterprise of a part of it. It has to come from the characteristic of the enterprise and the environment. As it is related to the managers in the first place, it is necessary to formulate the obligations and also the abilities of the managers. However, we are interested in the context of business ethics. Both literature and modern practice warn that in defining the system of doing business and strategy of management the starting point has to be business ethics. The reasons for this have their legal, social, political, and economic aspect. The legal orders of modern societies come from respecting human and civil freedoms and human and civil rights. Both these areas of rights and freedoms directly or indirectly cover the sector of doing business, i.e. ethics in doing business, as well. Legally and ethically the established enterprises contribute to strengthening social responsibility and respecting the institution of free market and fair competition. That is the basis of a liberal and democratic ideology and order derived from it.

The enterprises which develop moral relations among employees and also with consumers, associates, and partners in doing business, with no doubt, realize better results and represent more successful teams. On the previous pages we have pointed out why such relations create higher degree of mutual commitment, support, cooperation, assistance, trust, and solidarity among employed persons. For the same reasons the trust of a client to an enterprise and the quality of its goods and services increases. The employees are motivated for work, the productivity of work and quality of products improve and so does the profit, it is the interest of all to settle, cherish, and strengthen such the relations in a team. What would the system of doing business and especially strategy of management, have to keep in mind?

The relations with all employees have to be fair. They sometimes don't have to or because of some circumstances cannot be ideal, but all employees have to be treated equally. A different approach creates suspicion and dissatisfaction of people. A person who is not treated equally will not be devoted to the firm, he will be cautious in contacts with the others and that will reflect to the work results. Only the exceptional professionals who are beyond standards devoted to the profession will keep the same level of loyalty to the firm and with the same quality do their work obligation even if they are discriminated.

A management has to give adequate money compensations for the jobs the employees do on the basis of complexity, importance, quantity, and quality. Every employee should be paid identically for the same job.

An enterprise functions normally if professionalism and knowledge are respected there. In that sense we should be careful because of ethical reasons.

Not only a moral management but also a capable management will know why it is necessary to treat everybody equally and to practice identical relations to everybody. It means that nobody must be favored comparing to others for any reasons. Each of these reasons is extremely unjust and returns bad to the team.

If a management does not want to obey the rules of ethical doing business, but wants to manage in a completely contrary way, without the knowledge of the superiors (owners), then, it will have to rely on those persons whom it estimates as suitable for realization of their intentions. Dignity, honor, and professionalism will be changed for the position in the firm and at the expense of the colleagues. They would work according to the command of managers, spread false information, defamations, and intrigues, make conflict situations, if 
there are not affairs they would make them up. They would create bad atmosphere. Such the environment creates fear of employees, increases their dependence of the manager and his obedient. People in fear see things which do not exist. Maybe the points of view will not change, but the need will affect their behavior, acceptance, and agreement. The discord among individuals and groups cannot be avoided. The system then derives the worst characters of people. Because, those who are endangered, instead of moral will decide to protect their personal interest. That is why such phenomena and such so called managers exceptionally are harmful to a professional team, employees and also for a social environment out of the enterprise. If such the condition lasts for a longer period, a great damage will be done to the enterprise and the employed. The enterprise can come to the bankruptcy, too. No matter how such actions are covered and camouflaged by other activities, the reputation will be the first to be affected.

Psychological violence to employees is forbidden by Law in most countries in the world. However, it is practiced. Frightening, blackmailing, and threatening employees should provoke their fear and convince them to behave in the way the management wants them to behave. However, the results of such activities are pretty bad for the enterprise. Since psychological violence is mostly expressed through mobbing and discrimination, we will take the indicators related to these kinds of violence to the employees. According to the empiric investigations H. Loyman made a conclusion that because of mobbing a medium developed enterprise, loses averagely 30,000 to $100,000 \$$ per a worker-victim of mobbing. In Germany, the worker who is the victim of mobbing costs the enterprise from 25,000 to $75,000 €$ a year $^{13}$. It is enough to estimate what kind of damage to the enterprise it is. This is without considering the value dimension; it is clear why immoral and inhuman behaviors in a team should be prevented. Physical violence to an employee should also be added to this context. It also appears in the practice of enterprises.

A management must not use their personal positions in the firm for personal gains in any way. That also relates to the members of their families, friends and others. There are many ways and experience confirms that. The results, as in the previous examples, are the same.

Presenting fictive employees, forging accounts, taking money for works that have not been done, tax violations and other delinquent phenomena endanger employees and enterprises. Doing business on the foundations of frauds and scams, forge and many other immoral and delinquent activities sooner or later end with bad results. A regulated society sooner discovers and sanctions such phenomena. In unregulated and still close societies they are a kind of modus vivendi. On that base the system/anti-system functions until the true and complete social changes.

Revealing business secrets can be a profitable activity. With no doubt, it is immoral and illegal. There are no various motives. The interest is a predominant motive. A completely different thing is informing the state authorities on illegal activities in a firm, about the phenomena which are harmful and can make a great damage to a close and wider social environment.

Unlike these examples, we should develop moral relations in teams, build trusts and need for solidarity. Employees should be respected. You should respect them and try to make them aware of that. By that, their self respect will grow and also the pleasure and motivation to do their part of the job with much quality and to be completely loyal to the firm. To respect other people is not only the matter of someone's politeness and culture of behavior. It should be based on the consciousness of the importance of every member of the team for its

$\overline{13}$ Nikolić, Z. (2009). Mobing—uzroci, tipovi i posledice, Pravo i politika, 2, p. 47. 
proper functioning. Besides that, moral consideration to other people should not be neglected.

In a serious enterprise, which is profitable, it is necessary to formalize and procedurally determine the ways of expressing moral worry, one's own or somebody's threat. These rules and such surroundings which cherishes homely doing business and the relations derived from it, will reduce unethical behaviors as possible as it can. They always exist. But, it is different if it is about a sporadic act that appears from time to time and if we are dealing with something that usually happens. The freedom to report somebody's behavior that endangers an individual or a group, is one of the best prevention for them, or reducing to a small number of successive deviations of normal behavior.

For good managers it is said that they are squint-eyed, i.e. that in the same time they look at several directions. They should work on a good reputation of the enterprise. A harmonious surrounding in which people work, satisfaction of clients and associates in business will create a good reputation to the enterprise. The feedback is clear.

If it is capable, an enterprise should give money rewards to employees beyond the limits of determined salaries, whenever it is possible. Besides that, it is necessary to open.

The possibility of their promotions, assists them in some other ways according to the law and acts of enterprises, promotes them in a social community. A folk wisdom says: do the good and hope the good be returned to you. Once again we remind that the most successful companies are on the list of the most ethical enterprises in the world. It is not hard to understand why it is like that.

\section{References}

Abd-El-Salam, E. M., Shawky, A. Y., \& El-Nahas, T. (2013). The impact of corporate image and reputation on service quality, customer satisfaction and customer loyalty: Testing the mediating role. Case analysis in an international service company. The Business \& Management Review, 3(2), 177-196.

Crane, A., \& Matten, D. (2004). Business ethics: A European perspective. New York: Oxford University Press.

Daft, R. L., \& Marcic, D. (2009). Understanding management. Mason, Ohio: South-Western Cengage Learning.

Deal, T. E., \& Kennedy, A. A. (2000). Corporate cultures: The rites and rituals of corporate life. Persues Publishing.

Nikolić, Z. (2009). Mobing-uzroci, tipovi i posledice. Pravo i politika, 2, 47.

Nikolić, Z. (2011). Savremena sociologija. FIMEK, Novi Sad.

Nikolić, Z. (2015). Stavovi stanovnika Vojvodine o načinima zapošljavanja i osnovnim vrednostima u društvu, Zbornik Matice srpske za društvene nauke, 152, 597-617.

Nikolić, Z. (2016). Poslovna etika. FIMEK, Novi Sad.

Nordstrom, K. A., \& Ridderstrale, J. (1999). Funky business, talent makes capital dance. Stockholm: Bookhouse Publishing.

Peters, T., \& Waterman, R. H. (2008). U potrazi za izvjesnosnošću. Profil, Zagreb.

Singh, J. B. (1989). The teaching of ethics in Canadian schools of managements and administrative studies. Journal of Business Ethics, 51-56.

Zver, B. (1989). Poduzeće kao poslovni sistem. Zbornik radova Fakulteta organizacije i informatike, 245-256. 